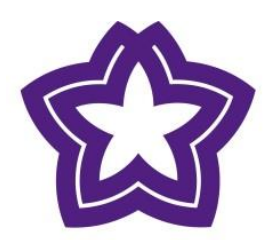

DALARNA

UNIVERSITY

Working papers in transport, tourism, information technology and microdata analysis

\title{
Estimated Lifetimes of Road Pavements in Sweden Using \\ Time-To-Event Analysis
}

Kristin Svenson

Editor: Hasan Fleyeh

Nr: 2013:30

Working papers in transport, tourism, information technology and microdata analysis

ISSN: $1650-5581$

(C) Authors 


\title{
Estimated Lifetimes of Road Pavements in Sweden
}

\section{Using Time-To-Event Analysis}

\author{
Kristin Svenson $^{1}$
}

\begin{abstract}
Maintenance planning of road pavement requires reliable estimates of roads' lifetimes. In determining the lifetime of a road, this study combines maintenance activities and road condition measurements. The scope of the paper is to estimate lifetimes of road pavements in Sweden with time to event analysis. The model used includes effects of pavement type, road type, bearing capacity, road width, speed limit, stone size and climate zone, where the model is stratified according to traffic load. Among the nine analyzed pavement types, stone mastic had the longest expected lifetime, 32 percent longer than asphalt concrete. Among road types, ordinary roads with cable barriers had 30 percent shorter lifetime than ordinary roads. Increased speed lowered the lifetime, while increased stone size (up to $20 \mathrm{~mm}$ ) and increased road width lengthened the lifetime. The results are of importance for life cycle cost analysis and road management.
\end{abstract}

CE Database subject headings: Pavement Management; Maintenance; Asphalt pavements Author keywords: Time-to-event analysis; Survival analysis; Road pavements; Maintenance planning

\section{INTRODUCTION}

To be able to perform long term maintenance plans for the Swedish road network, reliable estimations of maintenance intervals are needed. The condition of the road network in Sweden is monitored by regularly performed measurements on the road surface. Roughness (in terms of International Roughness Index, IRI) and rut depth are measured every one to five years. Since it is not economically or practically possible to conduct surface measures on all roads every year, prediction models are implemented in the Swedish Transport Administration's application Pavement

\footnotetext{
${ }^{1}$ PhD Candidate, Dept. of Statistics, Dalarna University, Borlänge. E-mail: kss@ du.se
} 
Management Systems (PMS) which cover all state roads in Sweden. These are linear models that lack in precision in the long run because the road wear is non linear. Normally, the rate of wear increases as the road ages. There is also a question of censored observations in the PMS database. These are roads which have only one registered maintenance activity, i.e. the next maintenance has not yet happened. If the censoring is not considered, such a model is likely to be biased and misleading.

A method widely used for non linear and censored data to estimate lifetimes in mechanistic applications is time-to-event analysis. In medicine, this method is known as survival analysis. Time-to-event analysis has been used to model lifetimes of roads where 'lifetime' is commonly defined as the interval between two maintenance activities (see e.g. Do 2011, Smith et al. 2006, Smith et al. 2005, Gharaibeh and Darter 2003, Hall et al. 1994). The aim of this paper is to estimate lifetimes of road pavement in Sweden with time-to-event analysis to provide reliable estimates for maintenance planning. In the planning process it is also of interest to analyze the impact of different variables on the road's expected lifetime; such as pavement type, road type, bearing capacity, road width, speed limit, stone size and climate zone. This will be obtained by fitting a Cox proportional hazards model to road data from the PMS database.

\section{LITERATURE REVIEW}

Time-to-event analysis has been used in previous research on lifetime estimation of road pavements. Estimated expected lifetimes of four maintenance activities on flexible pavement are included the US Long Term Pavement Performance (LTPP) program (Eltahan et al. 1999). A sample of 28 test sections were maintained in 1990 by the same contractor and then followed for eight years. Survival curves fitted from the non-parametric Kaplan-Meier product limit estimator are used to estimate the time to failure, where failure is defined as when a section meets the criteria for poor condition (mainly cracking). The authors conclude that survival analysis is suitable with pavement maintenance data. They recommend using larger datasets and possibly parametric methods to account for factors that affect pavement performance, and also better estimate the median lifetimes and cost-effectiveness. 
The Illinois Department of Transportation (IDOT) also use the Kaplan-Meier product estimator to find changes over time in expected pavement life and probability of failure (Gharaibeh and Darter 2003). The data consist of 1402 homogeneous sections with typical range from 0.5 to 5 miles in length, where each section is homogeneous with respect to design, construction history and traffic load. Termination of service life is defined as when a major rehabilitation action is carried out and results are presented as survival curves of six different pavement types. Smith et al. (2006) use a similar method to find the survival functions of stone mastic and hot mix asphalt using data from Wisconsin's Pavement Management Systems. However, their definition of a road's lifetime differ. To determine service life, the authors fit linear regressions with IRI and PDI (overall pavement condition indicator) as response variables. They apply threshold values of IRI and PDI stated in Wisconsin Department of Transportation's guidelines and estimate when each road section will pass this threshold. Roads with estimated service lives of 20 years or more are considered as censored.

Road condition in terms of fatigue cracking is the response variable in a time-to-event analysis performed by Wang et al. (2005). Their data consists of 486 asphalt concrete road sections and the failure of a section is defined by a threshold of 3.6 percent cracking. The study uses a parametric approach and it is found that the generalized gamma distribution is most appropriate for this data. Among several tested factors, thickness of asphalt concrete surface layer, thickness of concrete base, intensity of precipitation defined by wet days divided by total precipitation per year, and number of freeze/thaw cycles per year are found to have a significant effect on fatigue cracking. The researchers have a wide spread in their estimated lifetimes and therefore they conclude that the survival model seems more suitable for comparing and quantifying the effect of influencing factors, rather than predicting exact failure times of a pavement.

In a study by Do (2011) mean lifetimes of highways in South Korean are estimated. A classification based on traffic volume related variables, heavy vehicle related variables and directional characteristics distinguishes three types of roads: urban, rural and recreational. The data contains 30 urban road sections, 103 rural road sections and 47 recreation road sections. Do finds that the 
log-normal distribution is most suitable for urban roads and that recreation roads have closest fit to Weibull distribution. For rural roads, no distribution is found appropriate and therefore a nonparametric estimation is made. Results from the analysis show that urban roads have shorter mean life than rural and recreation roads. Do recommends for further research that more variables which could affect road lifetimes should be added to the models.

The literature review shows that both non-parametric and parametric methods have been used to estimate roads' lifetimes, defined as the time between maintenance activities or the time to failure according to some road condition criteria. However, the parametric approach requires specification of a distribution and no unanimous distribution can be found in the literature. The non-parametric Kaplan-Meier estimator cannot include influencing factors which is necessary in a model for maintenance planning. This study uses the semi-parametric Cox proportional hazards model in which no distribution is needed, but where covariates can be included. Also, the definition of a road's lifetime used in this study will combine both maintenance activities and road condition information in order to provide more accurate estimates of roads' lifetimes.

\section{MATERIALS AND METHODS}

\section{Data material and data cleaning}

The data material in this study is provided by the database in the Swedish Transport Administration's Pavement Management Systems (PMS). In 2012 it consisted of 390,966 observations representing homogeneous road sections. These sections are homogeneous with respect to characteristics such as pavement type, maintenance date, traffic load, road width, speed limit and axle load restrictions. Sections vary in length, from over 1 kilometer to only a few meters. To avoid influence from very short sections, only homogeneous sections that are 50 meters or longer are used in this study.

When a maintenance activity is carried out it is reported in the PMS database. The quality of the database varies as routine maintenance seldom is reported and periodic maintenance sometimes is not reported at all. The opposite scenario - that maintenance is reported but no maintenance has 
been performed - also occurs, often due to errors in location of the maintenance activity (Gustafsson and Lundberg 2009). In some cases, when maintenance is detected in data due to drastic changes (i.e. significantly lower values) in the measures of IRI and rut depth, a fictitious maintenance is inserted to the data. If a maintenance activity is registered but no significant changes are seen in IRI or rut depth, this registered maintenance is removed. However, all reported maintenance activities without effect on the road's condition are not necessarily errors. Road sections can be maintained although their condition is good, often because adjacent sections are bad. Keeping maintenance activities on good sections in the data and using them in further analysis can give misleading results. Estimated lifetimes will be shorter than they would have been if only bad sections were maintained. On the issue of maintenance planning, the interest is to know the road's potential lifetime - i.e when the road needs maintenance due to a bad condition. After cleaning, the data material used in further analysis consists of 266,614 homogeneous road sections.

\section{Variables}

The variables selected in this study are road type, road width, speed limit, bearing capacity class (BCC), max stone size of the pavement material used on the road, climate zone, pavement type and traffic load in terms of Average Annual Daily Traffic (AADT).

The PMS database contains six different road types: ordinary 2-lane roads, motorways, undivided motorways, 4-lane roads, ordinary roads with cable barriers and undivided motorways with cable barriers. The two latter types are also known as $2+1$ roads. In 1998, the Swedish Transport Administration started to rebuild some ordinary 2-lane roads (13 meters or wider) and undivided motorways. A cable barrier was installed and the lanes alternate between one and two. $2+1$ roads are safer than ordinary 2-lane roads. The rate of deathly accidents on $2+1$ roads has been lowered with 76 percent compared to an ordinary road with similar characteristics (Carlsson 2009).

The traffic load is reported as AADT; the average number of vehicles per day on a specific road section. The heavy traffic, defined as vehicles weighting over 3.5 tonnes, is calculated separately. In general, measures of AADT are more correct for high traffic roads (in this study, high traffic roads are defined as having an AADT of more than 4000) and more uncertain for low traffic 
roads (AADT less than 4000). Heavy traffic load estimations are very uncertain and therefore not included in the model (J. Lang, "Assessment and Analysis of Road Network Performance Using Long-Term Surface Condition Data", unpublished internal report, WSP Sweden/Swedish Transport Administration, 2011).

Bearing capacity classes (BCC) are coded from one to three, where one is the most common class. If there are axle road restrictions due to bearing capacity limitations a road can receive classification two or three, were the third class roads carries the least axle load.

Sweden is a heterogeneous country climate wise. The impact of ground frost and studded tyres vary both between and within counties. The influence of climate on road pavement lifetimes depends partly on the climate itself, but also on how much consideration the climate has been given in pavement design. The Swedish Transport Administration uses several climate zone classifications in their database, some according to geographical coordinates and some according to a simpler administrative classification based on counties. For convenience, the latter representation is used in this study. Sweden is divided into three climate zones: north, central and south.

The nine most common pavement types in Sweden are asphalt concrete, stone mastic, seal coat, grouted macadam, semi-hot mix, cold mix, hot mix, surface dressing on gravel and surface dressing. Asphalt concrete is used on all types of roads and in all traffic classes. Stone mastic is the most expensive material of the nine and it is used only on high traffic roads. Seal coat is a preventive maintenance activity designed to increase the remaining life of low traffic roads by some years until the roads need more thorough maintenance. Grouted macadam is an activity for low traffic roads. It is sometimes used as a preventive maintenance to cover only edges of the road, but can also be used to cover the whole road surface. Semi-hot mix is applied on roads with an AADT of less than 2000 vehicles. It is a softer, dynamic pavement mix that sometimes can heal from small cracks by its own movement. Cold mix is harder than semi-hot mix and mostly found on roads with AADT of 500-2000 vehicles. The advantage of cold mix is that it does not have to be strongly heated before paving. Surface dressing on gravel is basically paved gravel roads. The road is prepared and covered with a thin layer of asphalt. These roads are always low traffic roads. 
Hot mix is an older maintenance activity for high traffic roads. Surface dressing is mainly used on low traffic roads. It is a rough pavement that is smoothed out over time.

Spearman's rank correlation coefficients are calculated among all quantitative and ordinal variables except AADT. All correlation coefficients are significant. The traffic load has an impact on all other road characteristics and must therefore be treated separately. Road types are coded from 1 (motorway) to 6 (ordinary road with cable barrier). The rank can be motivated by road construction, where a lower number indicates a stronger construction. No variables had a higher pairwise correlation than $|0.37|$. Too highly correlated variables will violate the assumption of model estimates that describe a causal relationship. That is, if variables are strongly dependent, their estimates could be biased.

The highest correlations are found between road width and speed limit (positive correlation of 0.37 ) and between road width and road type (negative correlation of 0.34). It is natural that motorways are wider than other roads, and also that wide roads allow a higher speed.

\section{Time-to-event analysis}

As described by Klein and Moeschberger (2005), the basic concepts of time-to-event analysis are the following. First, consider the time to some event $X$ as a continuous nonnegative random variable from a homogeneous population. Henceforth, capital $X$ will denote a random variable and lower-case $x$ denotes fixed values.

The survival function $S(x)$ is the probability of an item surviving to time $\mathrm{x}$, i.e. that the event of interest has not occured at time $\mathrm{x}$. If an item has not experienced the event, it is denoted as right censored. Only right censoring is considered in this study.

Since $S(x)=\operatorname{Pr}(X>x)$ it is also, by definition equal to $S(x)=1-F(x)=\int_{x}^{\infty} f(t) \mathrm{d} t$, where $F(x)$ is the cumulative distribution function. Consequently, the probability density function in terms of the survival function is:

$$
f(x)=\frac{-\mathrm{d} S(x)}{\mathrm{d} x}
$$


The hazard rate function $h(x)$ is the chance that an item of age $\mathrm{x}$ experiences the event of interest in the next instant in time.

The hazard rate $h(x)$ is a limit defined as:

$$
h(x)=\lim _{\Delta x \rightarrow 0} \frac{\operatorname{Pr}(x \leq X<x+\Delta x \mid X \geq x)}{\Delta x}
$$

which can be interpreted in the way that $h(x) \Delta x$ is the approximate probability of an item of age $x$ experiencing the event of interest in the next instant. An increasing hazard rate can be understood as natural aging, i.e. that the probability of the event increases as the item becomes older. The hazard rate can be expressed in terms of the survival function:

$$
\begin{aligned}
h(x) & =\frac{f(x)}{S(x)} \\
& =\frac{-\mathrm{d} \ln S(x)}{\mathrm{d} x}
\end{aligned}
$$

\section{Cox proportional hazards model}

The model of choice in this study is Cox proportional hazards model (Cox 1972). The Cox model is semi-parametric and no assumptions regarding the distribution of the data are needed. Therefore the model is robust and the results are not biased by any misspecification.

The term proportional hazard refers to the fact that the ratio between the hazards of two individuals with different values of one covariate is constant in the Cox model. Data of sample size $n$ consists of three components $\left(T_{i}, \delta_{i}, Z_{i}(t)\right), i=1, \ldots, n$. $T_{i}$ is the time on study for item $i, \delta_{i}$ is an event indicator for item $i\left(\delta_{i}=1\right.$ if the event has occured, $\delta_{i}=0$ if right censored) and $Z_{i}(t)=\left(Z_{i 1}(t), \ldots, Z_{i p}(t)\right)$ is the vector of $p$ covariates for the $i$ th subject at time $t$ which may affect the the survival distribution of $X . Z_{i k}(t)$ 's may be time dependent.

The hazard rate at time $t$ is modelled directly, given the design matrix $\mathbf{Z}$ including all covariates. It consists of a baseline hazard rate $h_{0}(t)$ and a regression part $\mathbf{Z} \boldsymbol{\beta}$ : 


$$
h(t \mid \mathbf{Z})=h_{0}(t) \exp (\mathbf{Z} \boldsymbol{\beta})
$$

A non-parametric estimate of the baseline hazard function at time $t_{i}$ on the $i$ th event is:

$$
\hat{h}_{0}\left(t_{i}\right)=\frac{d_{i}}{\sum_{k \in R\left(t_{i}\right)} \exp \left(\mathbf{Z}_{k} \hat{\boldsymbol{\beta}}\right)}
$$

where $d_{i}$ is the number of events at time $t_{i}$ and $R\left(t_{i}\right)$ is the set of individuals that could experience the event at time $t_{i}$. The $\hat{\beta}$-estimates are obtained through maximization of a partial likelihood (Hosmer et al. 2008),

For a stratified model having $s$ strata, the hazard rate for each stratum $j$ is given by:

$$
h_{j}(t \mid \mathbf{Z})=h_{0 j}(t) \exp (\mathbf{Z} \boldsymbol{\beta}), \quad j=1, \ldots, s
$$

\section{Fitting the Cox model}

A stratified Cox proportional hazards model is fitted to data using the package 'Survival' (Therneau 2013) in the software R, version 2.15.1 (R Core Team 2012). The model have eight strata according to traffic classes stated by the Swedish Transport Administration (Table 2). The stratification is motivated by the nature of road construction. When a road is built or rebuilt it is adjusted according to the traffic load, which is the single most important factor in determining the thickness of construction needed. The construction defines the type of road, the speed limit, the road width, the pavement type and the bearing capacity.

A model with eight strata imply that the baseline hazard rate differs over traffic classes, but the effect of the covariates are the same over strata. In other words, the estimated parameter vector $\beta$ is constant for all traffic classes while the effect of traffic is incorporated within the differentiated baseline hazard. Hence, the dependency between traffic and all other covariates will not cause any bias in the $\beta$-parameters and the effects of the covariates can be interpreted individually (Klein and Moeschberger 2005).

As previously mentioned, the definition of a road's lifetime being the time between two mainte- 
nance activities has the drawback that the cause of maintenance is unknown. Gharaibeh and Darter (2003) mention that roads usually are maintained due to poor condition, but that this condition varies from section to section. Some sections might not yet have been maintained even though their condition is poor. To improve the analysis and obtain more accurate estimates of expected lifetimes, information on road surface measurements are added to the model. Rut depth and IRI have been recorded since 1987 in Sweden. The Swedish Transport Administration has developed a maintenance standard stating appropriate levels of rut depth and IRI (Trafikverket 2012). The maintenance standard is a recommendation and not a necessity. All road sections in the material where a measure of surface condition is available (about 170,000 out of 266,614 road sections in total) were compared to the limits in the maintenance standard. If the measures of rut depth or IRI of a censored section exceeded recommended values, it was labelled as "ought to have been maintained" and considered as non-censored in the analysis.

\section{RESULTS}

Large differences in estimated effects of road pavement types on roads' lifetimes were found (Table 3). Differences among road types are smaller but substantial. The effect of climate zone, bearing capacity and max stone size differ significantly but not as much as the previous two variables. The continuous variables road width and speed limit have smaller effect on roads' lifetimes, depending on the scale they are measured on.

\section{Effect of including road condition to define a road's lifetime}

The definition of a road's lifetime in this model is either the time between two maintenance activities, or - if the road has no second activity registered - the time between the first maintenance activity and the time when measurements of rut depth or IRI exceeds the limits in the maintenance standard.

In particular, the inclusion of road condition as response variable made a difference to $2+1$ roads. The oldest $2+1$ roads in the data are 13 years old and a lot of observations registered on this road type have censored lifetimes. When the surface condition of these roads were compared to the maintenance standard, censoring decreased from 57.3 to 52.1 percent. In total, 4.2 percent of 
the $2+1$ road sections which have not been maintained had measures of IRI and rut depth which exceeded the recommended limits in the maintenance standard.

A comparison of estimated median lifetimes between a model with and without road condition included as response variable is made (Table 5). With road condition included, the median lifetime of ordinary roads with cable barriers is one to three years shorter for all traffic classes.

\section{Survival curves}

The expected median lifetime is found where the survival proportion equals 0.5 (Figure 1). Each of the eight traffic class strata has a corresponding survival curve. It is clear from the figure that low traffic roads (traffic class 1-4) have longer expected lifetimes than high traffic roads (traffic class 5-8).

When fitting survival curves from the Cox model covariate values must be specified (see Table 4 for covariate values represented in Figure 1). For use in a maintenance planning setting, estimated lifetimes of each specific combination of covariates can be calculated and compared.

\section{DISCUSSION}

The extensive database available in the Swedish Traffic Administration's PMS application makes an excellent foundation for maintenance planning. The problem of censored maintenance intervals can be solved by time-to-event analysis. This study uses Cox proportional hazards model to estimate lifetimes and analyze the effect of seven different covariates on lifetimes of Swedish road pavements. To improve the accuracy of the estimated lifetimes, road condition (IRI and rut depth) was included in the model as response variable.

\section{Pavement types}

Asphalt concrete is chosen as reference category among pavement types because it is common within all traffic classes. Stone mastic has the smallest hazard ratio of 0.68 , indicating a lifetime that is 32 percent longer than asphalt concrete. Stone mastic is an expensive high traffic maintenance activity and it is in line with expectations that it has the longest lifetime.

Seal coat has the second highest probability of requiring maintenance in the next instant with a 
hazard ratio of 2.05 compared to the reference category. Because seal coat is a preventive maintenance to slightly increase the lifetime of a road, this estimation is credible.

Grouted macadam has a hazard ratio of 0.91 , but the estimate is not significant. This is a low traffic maintenance activity, sometimes used to cover just the edges of a road and sometimes used to cover the whole road. In the first scenario grouted macadam is only a preventive maintenance to increase the lifetime of a road by some years. It can be suspected that due to the cleaning of the data these activities have been removed. If only the edges of a road are remade, it will not affect measures of IRI and rut depth which are used to determine if a activity has effect or not. Hence, only road sections where the whole road surface is paved with grouted macadam are included in the model estimation.

Semi-hot mix has an expected lifetime that is 49 percent shorter than asphalt concrete. Cold mix has the shortest lifetime of all pavement types - 113 percent shorter than asphalt concrete. Cold mix is mostly present on older roads and not used a lot nowadays. Surface dressing on gravel has an expected lifetime that is 93 percent shorter than the reference category. This is a low traffic maintenance and it is expected to have a fairly short lifetime compared to asphalt concrete. Hot mix is a high traffic maintenance and its expected lifetime is 26 percent shorter than asphalt concrete.

Surface dressing is mainly used on low traffic roads with an AADT of up to 4000 vehicles. It is a rougher and cheaper material than asphalt concrete but with a similar expected lifetime, only eight percent shorter.

To conclude, pavement types used mostly on high traffic roads generally have longer expected lifetimes (i.e. smaller hazard ratios) than pavement types for low traffic roads. Since the estimates assume a situation where all other variables are fixed, this result is natural. When planning maintenance activities in practice all factors which influence a road's lifetime have to be considered at once.

\section{Road types}

The most common road type in Sweden is ordinary 2-lane roads and therefore it is chosen as the reference category. The estimates of undivided motorways and undivided motorways with 
cable barriers are not significant. There are very few sections belonging to these types of roads and a lot of them are censored. Motorways are expected to have a slightly longer life than ordinary 2-lane roads with a hazard ratio of 0.87 . This means that if motorways carried the same amount of traffic and all other covariates were the same for both road types, motorways would have a longer expected lifetime than ordinary 2 -lane roads. Swedish roads are generally constructed to carry a higher amount of traffic than they do at present to compensate for an increased future traffic load. The hazard ratio of motorways indicates that they are constructed to carry a greater increase in traffic load than ordinary 2-lane roads.

Studies by the Swedish National Road and Transport Research Institute (VTI) have shown that development of ruts on $2+1$ roads increase about twice as fast as ruts on ordinary 2-lane roads (Carlsson 2009). If $2+1$ roads are maintained according to the maintenance standard they should have shorter lifetimes than ordinary 2-lane roads. This assumption is confirmed by the Cox model estimates. In a model which only considers maintenance activities as response variable, the hazard ratio of undivided motorways with cable barrier was 0.98 (p-value 0.78303 ) and the hazard ratio of ordinary 2-lane roads with cable barrier was 1.13 (p-value 0.001). When including road condition as response variable, the hazard ratio of ordinary 2-lane roads with cable barrier increased to 1.30 , indicating a 30 percent shorter lifetime than ordinary 2-lane roads. The hazard ratio of 1.08 for undivided motorways with cable barriers is higher but still not significant.

4-lane roads are very similar to motorways but lack one or more factors needed for a motorway classification, such as restrictions for verges, junctions, speed limits etc that are not fulfilled. 4-lane roads have a hazard ratio of 0.62 which implies a longer lifetime than ordinary 2-lane roads. The same logic of construction as with motorways applies to 4-lane roads.

\section{Climate zones}

Climate zone central is chosen as reference category because it lies between the northern part of Sweden with very cold winters and the southern part with milder winters. The northern climate zone has a significant hazard ratio of 0.88 which indicates longer lifetimes for roads in the north. This result is somewhat unexpected since ground frost and the use of studded tires are factors with 
large impact on road condition. Hence the northern climate zone with longer winters would be expected to have shorter lifetimes than the south and central climate zones.

Historically, the southern part of Sweden has received more funding for road maintenance due to more intense traffic (J. Lang, WSP Sweden, personal communication, 2012). However, if maintenance in the northern zone was neglected due to budget restrictions it would have shown in measures of IRI and rut depth that exceeded the maintenance standard. This is not the case - the northern zone has longer expected lifetime even when adjusted for road condition. The explanation of the lower hazard ratio in the northern zone might actually be that the road construction is stronger in the north to compensate for the impact of ground frost.

\section{Bearing capacity class}

BCC 1 is by far the most common bearing capacity class in Sweden. Roads with other restrictions have some kind of weak element, e.g. bridges which do not allow heavy vehicles. Due to the restrictions heavy traffic will not choose these kinds of roads, and the wear will be much less than on roads with the standard bearing capacity which will carry heavy vehicles. BCC 2 has no significant effect, but a hazard ratio of 0.82 for BCC 3 indicates longer expected lifetimes when this restriction is imposed.

Max stone size

A max stone size of the pavement material of less than $10 \mathrm{~mm}$ is chosen as reference category. Roads with slightly larger stones have longer lifetimes - 7 percent longer for roads with maximum $15 \mathrm{~mm}$ stones and 13 percent longer for roads with max $20 \mathrm{~mm}$ stones. However, for roads with max stone size of $20 \mathrm{~mm}$ or larger, the lifetime is 3 percent shorter than the reference category.

\section{Continuous variables}

The continuous variables are road width and speed limit.

Road width show an expected increased lifetime the broader the road is with a hazard ratio of 0.99 for each decimeter. This means that if the road width is increased by 1 decimeter (i.e. from 90 decimeters to 91 decimeters), the lifetime is expected to increase with 1 percent. A wider road 
is expected to have a longer lifetime because drivers are known to avoid ruts if they can, which is possible on wider roads.

Speed reduces the lifetime of a road with a hazard ratio of 1.01 for each $10 \mathrm{~km} / \mathrm{h}$ increase in speed limit in a range from 30 to $120 \mathrm{~km} / \mathrm{h}$. If the speed limit is e.g. increased from $50 \mathrm{~km} / \mathrm{h}$ to 90 $\mathrm{km} / \mathrm{h}$, the risk of needing maintenance is expected to increase with $1.01^{4}=1.04$, i.e. the lifetime of roads with speed limit $90 \mathrm{~km} / \mathrm{h}$ is expected to be 4 percent shorter.

\section{CONCLUSIONS}

The results from the Cox proportional hazards model showed that stone mastic, asphalt concrete and surface dressing had the longest expected lifetimes among pavement types. Seal coat and cold mix had the shortest expected lifetimes. These results are in line with theory. Further research on life cycle costs of the different pavement types would be interesting, especially since surface dressing which is much cheaper than asphalt concrete had an almost equal hazard ratio.

Among road types it was shown that the inclusion of road condition made the estimated lifetimes of $2+1$ roads one to three years shorter than if road condition was not included in the model. This implies that there are some $2+1$ roads in Sweden that have not been maintained although they are in a poor condition according to the maintenance standard. Ordinary roads with cable barriers had 30 percent shorter lifetimes than ordinary 2-lane roads. Hence, if the Swedish Traffic Administration continues to rebuild 2-lane roads into $2+1$ roads the need of road maintenance will increase.

Climate zone north had the longest expected lifetime, which was slightly unexpected because of harder winters in the north. A more fine tuned climate zone categorization might be preferred in future research.

A bearing capacity limitation was showed to increase roads' lifetimes. Max stone size had a somewhat ambiguous effect: up to 20 millimeters an increased stone size also increased lifetimes, but stones over 20 millimeters gave a decrease in lifetimes. Increased road width and decreased speed limit proved to increase lifetimes. 


\section{REFERENCES}

Carlsson, A. (2009). "Evaluation of 2+1 roads with cable barrier." Report No. 636A, VTI Rapport.

Cox, D. (1972). "Regression models and life-tables." Journal of the Royal Statistics Society, 34(2), $187-220$.

Do, M. (2011). “Comparative analysis on mean life reliability with functionally classified pavement sections.” KSCE Journal of Civil Engineering, 15(2), 261-270.

Eltahan, A., Daleiden, J., and Simpson, A. (1999). "Effectiveness of maintenance treatments of flexible pavements." Transportation Research Record: Journal of the Transportation Research, 1680(1), $18-25$.

Gharaibeh, N. and Darter, M. (2003). "Probabilistic analysis of highway pavement life for illinois." Transportation Research Record: Journal of the Transportation Research Board, 1823, 111120.

Gustafsson, M. and Lundberg, T. (2009). “Prognosmodeller för tillståndsmått i trafikverkets pavement management systems.” Report No. 765, VTI Rapport.

Hall, K., Lee, Y., Darter, M., and Lippert, D. (1994). "Forecasting pavement rehabilitation needs for illinois interstate highway system." Transport Research Record: 73d Annual Meeting, Washington DC, 1455, 116-122.

Hosmer, D., Lemeshow, S., and May, S. (2008). Applied Survival Analysis: Regression Modeling of Time-to-Event Data. Wiley and Sons, New Jersey, 2nd edition.

Klein, J. and Moeschberger, M. (2005). Survival Analysis - Techniques for Censored and Truncated Data. Springer, New York, 2nd edition.

R Core Team (2012). R: A Language and Environment for Statistical Computing. R Foundation for Statistical Computing, Vienna, Austria. ISBN 3-900051-07-0.

Smith, K., Titus-Glover, L., Darter, M., Quintus, H. V., Substad, R., and Hallin, J. (2005). “Evaluation of the cost benefits of continous pavement preservation design strategies versus reconstruction: Final rep. 491." Report No. FHWA-AZ-05-491, Arizona Department of Transportation (September). 
Smith, K., Titus-Glover, L., Rao, S., Quintus, H. V., and Stanley, M. (2006). "Life-cycle cost analysis of sma pavements and sma application guidelines." Report No. WHRP 06-11, Wisconsin Highway Research Program (August).

Therneau, T. M. (2013). A Package for Survival Analysis in S. R package version 2.37-4.

Trafikverket (2012). “Underhållsstandard belagd våg 2011.” Report No. 2012:074.

Wang, Y., Mahboub, K., and Hancher, D. (2005). "Survival analysis of fatigue cracking for flexible pavements based on long-term pavement performance data." Journal of Transport Engineering, 131(8), 608-616. 


\section{List of Tables}

1 Correlation matrix of model covariates. . . . . . . . . . . . . . . . 19

2 Definition of traffic classes. . . . . . . . . . . . . . . 20

3 Cox proportional hazards model with maintenance and road condition as response

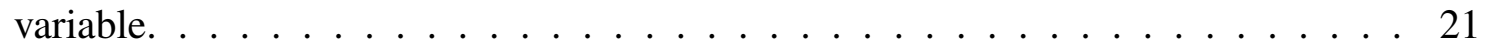

4 Covariate values in estimated survival curves. . . . . . . . . . . . . . . . 22

5 Comparison of median lifetimes for ordinary roads with cable barrier. Other covariate values as in Table $4 \ldots \ldots \ldots \ldots \ldots$ 
TABLE 1. Correlation matrix of model covariates.

\begin{tabular}{|c|c|c|c|c|c|c|}
\hline \multicolumn{7}{|c|}{$\begin{array}{c}\text { Spearman's correlation coefficients. } \\
\text { Number of observations. }\end{array}$} \\
\hline & Road width & $\mathrm{BCC}$ & Speed limit & Max stone & Road type & Climate zone \\
\hline \multirow[t]{2}{*}{ Road width } & 1.00 & -0.15 & 0.37 & -0.15 & -0.34 & 0.13 \\
\hline & 266614 & 266465 & 266420 & 251771 & 260386 & 239596 \\
\hline \multirow[t]{2}{*}{$\mathrm{BCC}$} & -0.15 & 1.00 & -0.09 & 0.03 & 0.04 & 0.03 \\
\hline & 266465 & 266614 & 266553 & 251903 & 260395 & 239720 \\
\hline \multirow[t]{2}{*}{ Speed limit } & 0.37 & -0.09 & 1.00 & 0.08 & -0.37 & 0.21 \\
\hline & 266420 & 266553 & 266614 & 251859 & 260349 & 239700 \\
\hline \multirow[t]{2}{*}{ Max stone } & -0.15 & 0.03 & 0.08 & 1.00 & 0.03 & 0.24 \\
\hline & 251771 & 251903 & 251859 & 266614 & 245836 & 226523 \\
\hline \multirow[t]{2}{*}{ Road type } & -0.34 & 0.04 & -0.37 & 0.03 & 1.00 & 0.13 \\
\hline & 260386 & 260395 & 260349 & 245836 & 266614 & 233804 \\
\hline \multirow[t]{2}{*}{ Climate zone } & 0.13 & 0.03 & 0.21 & 0.24 & 0.13 & 1.00 \\
\hline & 239596 & 239720 & 239700 & 226523 & 233804 & 266614 \\
\hline
\end{tabular}


TABLE 2. Definition of traffic classes.

\begin{tabular}{cl}
\hline Class & Vehicles/day \\
\hline 1 & $<250$ \\
2 & $250-499$ \\
3 & $500-999$ \\
4 & $1000-1999$ \\
5 & $2000-3999$ \\
6 & $4000-7999$ \\
7 & $8000-11999$ \\
8 & $>12000$ \\
\hline
\end{tabular}


TABLE 3. Maximum likelihood estimates of the Cox proportional hazards model with maintenance and road condition as response variable. (Stratification: 8 traffic classes)

\begin{tabular}{|c|c|c|c|c|c|}
\hline Parameter & $\begin{array}{l}\text { Parameter } \\
\text { Estimate }\end{array}$ & $\begin{array}{l}\text { Standard } \\
\text { Error }\end{array}$ & Z-value & P-value & $\begin{array}{l}\text { Hazard } \\
\text { Ratio }\end{array}$ \\
\hline \multicolumn{6}{|l|}{ Asphalt concrete $^{\star}$} \\
\hline Stone mastic & -0.385 & 0.0149 & -25.8 & $<.0001$ & 0.68 \\
\hline Seal coat & 0.719 & 0.0367 & 19.6 & $<.0001$ & 2.05 \\
\hline Grouted macadam & -0.091 & 0.0650 & -1.4 & 0.1622 & 0.91 \\
\hline Semi-hot mix & 0.400 & 0.0102 & 39.1 & $<.0001$ & 1.49 \\
\hline Cold mix & 0.755 & 0.0238 & 31.7 & $<.0001$ & 2.13 \\
\hline Surface dressing on gravel & 0.656 & 0.0124 & 52.8 & $<.0001$ & 1.93 \\
\hline Hot mix & 0.246 & 0.0154 & 16.0 & $<.0001$ & 1.28 \\
\hline Surface dressing & 0.075 & 0.0081 & 9.3 & $<.0001$ & 1.08 \\
\hline \multicolumn{6}{|l|}{ Ordinary 2-lane road ${ }^{\star}$} \\
\hline Motorway & -0.133 & 0.0236 & -5.6 & $<.0001$ & 0.88 \\
\hline Undivided motorway & -0.125 & 0.1477 & -0.8 & 0.3968 & 0.88 \\
\hline Undivided motorway $\mathrm{w} / \mathrm{cb}^{\dagger}$ & 0.082 & 0.0578 & 1.4 & 0.1549 & 1.09 \\
\hline 4-lane road & -0.425 & -0.471 & -12.4 & 0.0379 & 0.62 \\
\hline Ordinary road $\mathrm{w} / \mathrm{cb}^{\dagger}$ & 0.262 & 0.0343 & 7.6 & $<.0001$ & 1.30 \\
\hline \multicolumn{6}{|l|}{ Climate zone central $^{\star}$} \\
\hline Climate zone north & -0.133 & 0.0090 & -14.8 & $<.0001$ & 0.88 \\
\hline Climate zone south & -0.050 & 0.0074 & -6.7 & $<.0001$ & 0.95 \\
\hline \multicolumn{6}{|l|}{ Bearing capacity class 1 * } \\
\hline Bearing capacity class 2 & 0.002 & 0.0220 & 0.1 & 0.9294 & 1.00 \\
\hline Bearing capacity class 3 & -0.196 & 0.0720 & -2.7 & 0.0066 & 0.82 \\
\hline \multicolumn{6}{|l|}{ Max stone size $<10 \mathrm{~mm}^{\star}$} \\
\hline Max stone size $10-14.9 \mathrm{~mm}$ & -0.073 & 0.0121 & -6.1 & $<.0001$ & 0.93 \\
\hline Max stone size $15-19.9 \mathrm{~mm}$ & -0.138 & 0.0122 & -11.3 & $<.0001$ & 0.87 \\
\hline Max stone size $\geq 20 \mathrm{~mm}$ & 0.032 & 0.0145 & 2.2 & 0.0264 & 1.03 \\
\hline Road width (dm) & -0.004 & 0.0002 & -17.6 & $<.0001$ & 0.99 \\
\hline Speed limit $(\mathrm{km} / \mathrm{h})$ & 0.007 & 0.0002 & 31.2 & $<.0001$ & 1.01 \\
\hline \multicolumn{6}{|c|}{$\begin{array}{l}\text { Number of observations used in analysis: } 220699 \text {. } \\
{ }^{*} \text { is the reference category of each variable. } \\
{ }^{\dagger} \text { w/cb = with cable barrier. }\end{array}$} \\
\hline
\end{tabular}


TABLE 4. Covariate values in estimated survival curves.

\begin{tabular}{ll}
\hline Variable & Value \\
\hline Pavement type & Asphalt concrete \\
Road type & Ordinary 2-lane road \\
Climate zone & Central \\
Bearing capacity class & 1 \\
Road width $(\mathrm{m})$ & 7.5 \\
Speed limit $(\mathrm{km} / \mathrm{h})$ & 80 \\
Max stone size & 14 \\
\hline
\end{tabular}


TABLE 5. Comparison of median lifetimes for ordinary roads with cable barrier. Other covariate values as in Table 4.

\begin{tabular}{|c|c|c|c|c|c|c|}
\hline \multirow[b]{2}{*}{$\begin{array}{l}\text { Traffic } \\
\text { class }\end{array}$} & \multicolumn{3}{|c|}{$\begin{array}{l}\text { Model with maintenance activity } \\
\text { as response variable }\end{array}$} & \multicolumn{3}{|c|}{$\begin{array}{l}\text { Model with maintenance activity } \\
\text { and road condition as response variable }\end{array}$} \\
\hline & $\begin{array}{l}\text { Median } \\
\text { lifetime }\end{array}$ & $0.95 \mathrm{LCL}^{\star}$ & $0.95 \mathrm{UCL}^{\star \star}$ & $\begin{array}{l}\text { Median } \\
\text { lifetime }\end{array}$ & $0.95 \mathrm{LCL}^{\star}$ & $0.95 \mathrm{UCL}^{\star \star}$ \\
\hline 1 & 26 & 25 & 28 & 23 & 22 & 24 \\
\hline 2 & 21 & 19 & 22 & 18 & 17 & 19 \\
\hline 3 & 18 & 17 & 19 & 16 & 15 & 17 \\
\hline 4 & 14 & 14 & 15 & 13 & 12 & 14 \\
\hline 5 & 12 & 12 & 12 & 11 & 11 & 11 \\
\hline 6 & 10 & 9 & 10 & 9 & 9 & 9 \\
\hline 7 & 9 & 8 & 9 & 8 & 8 & 8 \\
\hline 8 & 8 & 8 & 8 & 7 & 7 & 7 \\
\hline
\end{tabular}




\section{List of Figures}

1 Estimated survival curves from Cox proportional hazards model. . . . . . . . . . . 25 
Fitted survival curves from Cox Proportional Hazards model

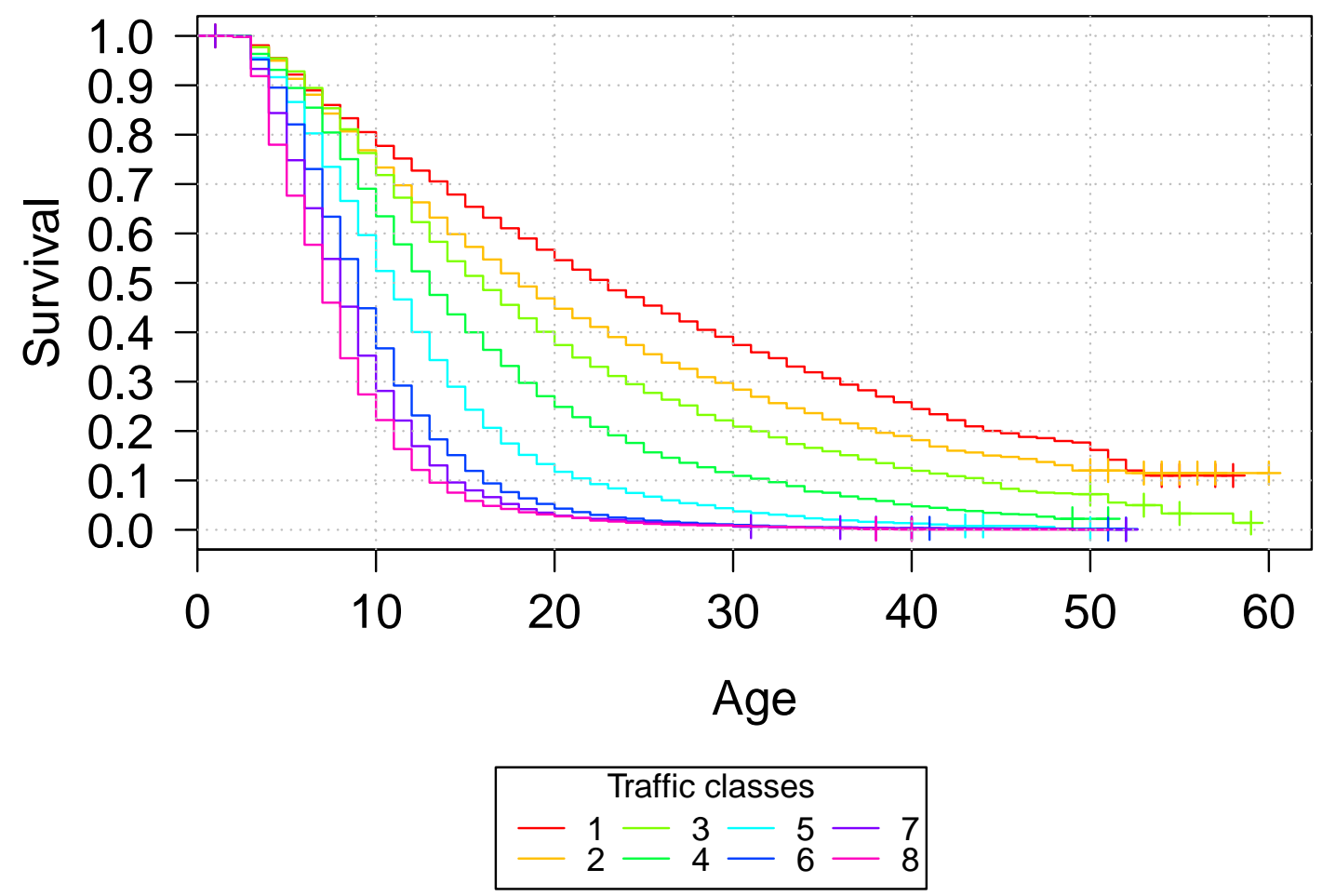

FIG. 1. Estimated survival curves from Cox proportional hazards model. 